\title{
ENTRE SAMBA E BRILHO: \\ a produção dos corpos nos carnavais da Unidos da Rheingantz
}

\author{
Priscila Fontes Gularte \\ Leila Cristiane Pinto Finoqueto \\ Rodrigo Lemos Soares
}

\section{Resumo}

O presente trabalho tem como objetivo analisar como são produzidos os corpos dentro de uma escola de samba localizada no extremo Sul do Rio Grande do Sul, estabelecendo uma articulação entre a produção dos corpos, o carnaval e o samba. Para o desenvolvimento desta pesquisa foram realizadas entrevistas semiestruturadas a uma amostra composta por oito sujeitos, sendo que seis desses são integrantes do grupo show da Sociedade Carnavalesca e Cultural Unidos da Rheingantz e dois são pessoas envolvidas com a memória/história do carnaval riograndino. O corpo, ao longo de 60 anos, ganhou visibilidade e relevância no interior do carnaval, assumindo a centralidade ao dar maior destaque aos contornos do que aos tecidos e adornos. Percebe-se, assim, um movimento que não é uniforme, mas indica, fortemente, a exacerbação do corpo pelos seus aspectos estéticos que devem se sobressair, mesmo que isso implique a negação, em alguns casos, do próprio corpo que se tem/é.

Palavras-chave: carnaval; produção dos corpos; educação física; práticas discursivas.

\section{BETWEEN SAMBA AND BRIGHTNESS: bodies production in Unidos da Rheingantz carnivals}

\begin{abstract}
The present work has as objective analyze how are the bodies produced inside of a samba school. Articulates bodies production, carnival and samba. To the research development were realized semi-structured interviews with six members of show group Society Carnival and Cultural Unidos da Rheingantz and two people involved with the memory/history of riograndino carnival, totaling so, eight subjects. The bodies, along 60 years, has won visibility and relevance in carnival inland. Assumed the centrality when giving biggest highlight to shape instead of fabrics and adornments. We realize so, that the moviment it`s not uniform, but indicates, tightly, the exarcerbation of bodie by its aesthetic aspects that must stand out, even if it implies the denial, in some cases, own body that has, that is.
\end{abstract}

Keywords: carnival; bodies production; physical education; dircursive practices.

\section{ENTRE SAMBA Y BRILLIANCE: la producción de cuerpos en el carnavais Unidos da Rheingantz}

Resumen

El presente trabajo tiene como objetivo analizar cómo se producen los cuerpos dentro de una escuela de samba. Articula la producción de cuerpos, carnaval y samba. Para el desarrollo de la investigación, se realizaron entrevistas semiestructuradas con seis miembros del grupo de espectáculos de la Sociedad de Carnaval y Cultural Unidos da Rheingantz y dos personas involucradas con la memoria/historia del carnaval riograndino, por lo tanto total de ocho temas. El cuerpo, de más de 60 años, ha ganado visibilidad y relevancia dentro del carnaval. Asumió la centralidad dando mayor protagonismo a los contornos que las 
telas y adornos. Por lo tanto, percibimos el movimiento que no es uniforme, pero indica fuertemente la exacerbación del cuerpo por sus aspectos estéticos que deben destacar, incluso si esto implica la negación, en algunos casos, del mismo cuerpo que uno tiene/es.

Palabras clave: carnaval; producción de cuerpos; educación física; prácticas discursivas.

\section{NA CONCENTRAÇÃO ${ }^{1}$}

O presente texto é fruto do meu Trabalho de Conclusão de Curso (TCC) de Licenciatura em Educação Física (EF) da Universidade Federal do Rio Grande - FURG, o qual articula corpo, produção dos corpos, carnaval e samba. Essa articulação problematiza discursos que produzem determinados tipos de saberes sobre os corpos e suas possibilidades de ser/ter o corpo para o carnaval. Para dar encaminhamentos ao decorrer do trabalho, primeiro irei transcorrer por alguns caminhos a fim de situar e identificar pontos necessários que auxiliarão no entendimento sobre os objetivos desta pesquisa.

A minha adesão ao carnaval ocorre no ano de 1994, com três anos de idade, quando participo pela primeira vez da ala das crianças na escola de samba Império Serrano. Desde então, minha participação é ativa, passando pelo conjunto acadêmico (grupo de pessoas que tocavam e cantavam samba, realizando a abertura oficial do carnaval da cidade do Rio Grande/RS), assim como em blocos e escolas de samba.

Herança da minha avó (Joana), o samba e o carnaval sempre estiveram presentes na minha família e, de alguma forma, todos/as têm ou já tiveram algum envolvimento com o carnaval².

A partir disso, sinto-me imersa no "mundo" do carnaval e, no passar dos tempos, tenho me questionado sobre como ocorrem os processos de decisão e de escolha dos corpos dentro de uma escola de samba. Uma das minhas inquietações diz respeito ao samba no pé: se esse é, de fato, o diferencial para escolher a rainha de uma escola ou se, na hora da seleção, é escolhido o "melhor" corpo, relegando o samba em si para o segundo lugar. Esses questionamentos sempre se fizeram presentes desde que comecei a participar ativamente de eventos e concursos pela escola de samba, intrigando-me a relação entre o carnaval e o corpo.

Nesse sentido, Goellner (2008) auxilia na compreensão do corpo enquanto um fenômeno atravessado pelos discursos que instituem modos possíveis de ser/ter corpo,

[...] a linguagem tem o poder de nomeá-lo classificá-lo, definir-lhe normalidades e anormalidades, instituir, por exemplo, o que é considerado um corpo belo, jovem e saudável. Representações estas que não são universais nem mesmo fixas [...]. É também onde se educa porque diferentes marcas se incorporam ao corpo a partir de distintos processos educativos presentes na escola, mas não apenas nela, visto que há sempre várias pedagogias em circulação. Filmes, músicas, revistas e livros, imagens, propagandas são também locais pedagógicos que estão, o tempo todo, a dizer de nós, seja pelo que exibem ou pelo que ocultam. Dizem também de nossos corpos e, por vezes, de forma tão sutil que nem mesmo percebemos o quanto somos capturadas/os e produzidas/os pelo que lá se diz (GOELLNER, 2008, p. 29).

\footnotetext{
${ }^{1}$ É o lugar onde a escola se organiza antes de entrar na avenida.

2 Desde auxiliares e costureiras, destaques de carro alegórico, passistas, porta-bandeira, passando por puxadores e cavaquinistas, comissão de frente, chefe de ala, ala de passo marcado, até o apoio à escola de samba.
} 
DOI: r $10.12957 /$ teias.\%Y.49589

O corpo, ao longo de sua história, passou por diversos estudos e ressignificações.

Uma versão moderna do dualismo não opõe mais o corpo ao espírito ou à alma, porém, mais precisamente, ao próprio sujeito. O corpo não é mais apenas, em nossas sociedades contemporâneas, a determinação de uma identidade intangível, a encarnação irredutível do sujeito, o ser-no-mundo, mas uma construção, uma instância de conexão, um terminal, um objeto transitório e manipulável suscetível de muitos emparelhamentos (LE BRETON, 2013, p. 28).

Ou seja, relacionando esses corpos ao carnaval, são corpos que estão suscetíveis a mudanças para se enquadrar às normas ou regras de sua escola de samba, ao seu contexto ou à sua realidade. São sujeitos que se modificam e se sujeitam às modificações para estar e permanecer nesse contexto.

$\mathrm{O}$ ingresso no curso de EF acendeu outras possibilidades de olhar as experiências que possuo do carnaval. Essa manifestação artística/popular/cultural sempre me motivou e me constituiu. No entanto, foi a partir da graduação, com as discussões sobre os corpos, instigadas nas aulas, que passei a problematizar a relação entre o carnaval e o corpo.

Alguns questionamentos, como o ideário de corpo perfeito, do corpo belo, no qual se excluem os corpos que não fazem parte desse padrão ou que não podem fazer parte de certos "locais" ou "posições" dentro de uma escola de samba interpelaram-me ao longo das minhas vivências no carnaval. Atrelado a isso, está o carnaval difundido pela mídia televisiva, que hoje é uma das maiores influências dos grandes carnavais e de seus espectadores. Como exemplo, cito o carnaval da cidade do Rio de Janeiro, o qual produz um ideário de corpo que enfatiza as musas, as madrinhas e as rainhas através de seus corpos torneados, definidos e malhados.

Assim, com o intuito de situar esta pesquisa e dar uma visibilidade acerca das condições de produção dessa temática, desenvolvi uma busca sobre o que vem sendo produzido na área da Educação Física a respeito do corpo e do carnaval. Para tanto, pesquisei em quatro revistas online da área da Educação Física, as quais tive maior proximidade no decorrer da graduação, sendo elas: Motrivivencia $^{3}$; Movimento ${ }^{4}$; Pensar a prática e Revista Brasileira de Ciências do Esporte (RBCE) ${ }^{6}$. Nessa busca, utilizei as seguintes palavras-chave: carnaval; samba; constituição dos corpos; produção dos corpos, filtrando as publicações dos últimos cinco anos, delimitando o período de janeiro de 2013 a setembro de 2018.

Com essa busca pelas produções acadêmicas no âmbito da EF relacionada à "produção e constituição dos corpos" e "samba/carnaval" não identifiquei nenhuma produção específica. Encontrei três produções com a palavra-chave carnaval, que se desenvolvia na relação de futebol e carnaval ou aberturas de eventos esportivos. Já na busca com a palavra-chave samba totalizou sete resultados, dos quais dois se repetiram com a palavra carnaval, de maneira geral fazendo ligação entre EF, cultura e samba, bem como relacionados à Copa do Mundo e ao espetáculo de abertura. Além desses, também destaco o papel do esporte nas medidas socioculturais das políticas públicas desenvolvidas dentro de uma escola de samba. Com a palavra-chave constituição dos corpos, obtive um total de 37 produções, mas nenhuma voltada para a relação corpo/carnaval. E, por

\footnotetext{
${ }^{3}$ Disponível em https://periodicos.ufsc.br/index.php/motrivivencia Acesso em 06 de set. de 2018.

${ }^{4}$ Disponível em https://seer.ufrgs.br/Movimento Acesso em 06 de set. de 2018.

${ }^{5}$ Disponível em https://www.revistas.ufg.br/fef Acesso em 06 de set. de 2018.

${ }^{6}$ Disponível em http://rbceonline.org.br/ Acesso em 06 de set. de 2018.
} 
DOI: r $10.12957 /$ teias.\%Y.49589

último, com a palavra-chave produção dos corpos, encontrei 78 resultados, porém, nenhum deles fazia referência ao corpo/carnaval.

$\mathrm{Na}$ sequência dos resultados obtidos, entendi que o desenvolvimento desta pesquisa pode contribuir para o âmbito acadêmico da Educação Física, promovendo um olhar sobre o corpo e carnaval sob a ótica da reflexão de como são produzidos esses corpos no interior de uma escola de samba.

Assim, apresento como problema de pesquisa a seguinte questão: como os integrantes da Sociedade Carnavalesca e Cultural Unidos da Rheingantz percebem a produção dos seus corpos para o carnaval? Para tanto, foram elaborados objetivos específicos para auxiliar na construção dessa investigação, a saber: conhecer práticas discursivas presentes na S.C.C Unidos da Rheingantz acerca do corpo para/do carnaval; identificar como são produzidos os corpos a partir da visão dos/as integrantes da S.C.C Unidos da Rheingantz; analisar as narrativas de sujeitos envolvidos com o carnaval em Rio Grande/RS e suas percepções sobre o corpo e o samba.

\section{COMISSÃO DE FRENTE ${ }^{7}$ : NOTAS INTRODUTÓRIAS DO CARNAVAL NO BRASIL}

Para entender o corpo neste processo de carnaval pesquisei como se deu a história do carnaval no Brasil num contexto geral. Reconheço que essas manifestações passaram e passam até hoje por novas reformulações. Conforme Cortês (2000), o carnaval no país surgiu das festas portuguesas, ligada aos "entrudos", que eram brincadeiras carnavalescas onde a "regra" era molhar e sujar os participantes de farinha, lama e limões de cera cheia de água de cheiro.

O carnaval do Rio de Janeiro tem sua origem relacionada à união entre o samba de roda (originalizado do batuque), da música popular (marchinhas carnavalescas) e dos ranchos ou cordões que eram compostos por foliões que tocavam instrumentos de sopro e corda. O samba se deu através do batuque, ritmo trazido pelos sujeitos escravizados sequestrados da África, no qual, aos poucos, foi incorporando outros instrumentos e elementos, modificando e construindo uma identidade brasileira. Assim, o samba expandiu-se através desses sujeitos escravizados para outras regiões brasileiras, transformando-se em uma expressão fortemente marcada por seus movimentos e ritmos (CORTÊS, 2000).

Ainda, segundo Cortês (2000), no ano de 1928, na cidade do Rio de Janeiro, surgia a primeira escola de samba fundada pelo sambista Ismael Silva, a "Deixa Falar". Logo em seguida, no ano de 1932, acontecia o primeiro desfile extraoficial das escolas de samba. Diferentemente do que foi o carnaval nessa época, hoje, assisto a desfiles de escolas de samba com riquezas em detalhes que, a cada ano, renovam-se buscando inserir novas tecnologias para deixar a escola mais próxima da realidade do tema-enredo escolhido.

\section{EVOLUÇÃO ${ }^{8}$}

Para o desenvolvimento desta pesquisa utilizei uma investigação de caráter qualitativo “[...] que se centra na descrição, análise e interpretação das informações recolhidas durante o processo

\footnotetext{
7 Grupamento que, à frente do abre-alas (primeiro carro alegórico), tem no desfile a função de apresentar a escola de samba ao público e ao corpo de jurados.

${ }^{8}$ É a forma como os componentes se movimentam no decorrer do desfile, de maneira harmônica e contínua.
} 
DOI: r 10.12957/teias.\%Y.49589

investigatório, procurando entendê-las de forma contextualizada [...]” (NEGRINE, 2006, p. 61). Esta investigação foi realizada na S.C.C Unidos da Rheingantz, após a autorização concedida pela presidente da escola, por meio do Termo de Consentimento Livre e Esclarecido, para o acesso a materiais que contam a história da escola nos seus 43 anos de existência, tais como fotos, reportagens em jornais e toda a documentação necessária para a conclusão da pesquisa.

A fim de entender como se constituiu essa escola, busquei a memória de um dos fundadores ${ }^{9}$, o qual participou da primeira reunião que deu início à história da Rheingantz. Esse contou que a S.C.C Unidos da Rheingantz foi fundada no dia 10 de abril de 1976, no Beco da Rheingantz, diante da casa de número 35, na esquina. Ali estavam reunidos os primeiros fundadores do então "Bloco Carnavalesco Unidos da Rheingantz", que se origina pela iniciativa de um grupo de amigos, moradores da Avenida Rheingantz, com o objetivo de se divertir no período de carnaval. Todos os fundadores da escola eram trabalhadores da Fábrica Rheingantz ${ }^{10}$. Quando a escola foi fundada, essa fábrica já tinha encerrado suas atividades, decretando falência, e foi reaberta com outro nome social, a Cia. Inca Têxtil.

O primeiro movimento feito foi a decisão pela criação de um bloco. O nome seria decidido na semana seguinte, em uma reunião com todos os fundadores. No dia 17 de abril 1976 foi realizada a segunda reunião para a decisão do nome da nova entidade carnavalesca que estava surgindo em Rio Grande/RS. Entre um café e outro, muitas sugestões surgiram, mas nenhuma do agrado de todos. Foi então que Dona Zélia Fonseca Centurion, enquanto lavava a louça do café, perguntou: "Por que vocês não colocam o nome de Unidos da Rheingantz?". Todos aprovaram a sugestão, ficando então o nome de Bloco Carnavalesco Unidos da Rheingantz. Após esse primeiro movimento, o Sr. Daniel Santana abriu as portas de sua casa, que em época de carnaval seria transformada em sede do bloco, casa de número 156 na Avenida Rheingantz, onde se instalou durante três carnavais, nos anos 1977, 1978 e 1979.

A partir de uma reivindicação da comunidade e dos fundadores da Rheingantz, foi solicitada uma autorização aos diretores da Fábrica Cia. Inca Têxtil para utilização do prédio de uma escola de ensino primário, a Comendador Rheingantz, que estava desativada desde 1970, para ser a sede da entidade, permanecendo ali durante os anos de 1980 a 1988.

Nesse tempo de atuação, o bloco trouxe como títulos os carnavais de 1978 a 1980, consagrando-se tricampeã. No ano seguinte, em 1981, o bloco passa para a categoria de escola de samba disputando com Império Serrano, Mariquitas, Praianas e Nega Tereza, conquistando o título de vice-campeã. Em 1983, a escola ou bloco retorna a obter o título de campeã do carnaval da cidade do Rio Grande. O ano de 1988 foi o último carnaval da escola, que se licenciou junto à Associação Riograndina de Entidades Carnavalescas (ARGEC), ficando, assim, desativada por 19 anos.

A escola retornou para o carnaval riograndino por meio da iniciativa de um grupo de amigos, que formalizou a Sociedade Carnavalesca e Cultural "Unidos da Rheingantz" registrada em ata em 17 de dezembro de 2007. A escola retornou visando realizar atividades culturais em sua sede provisória, no "União Fabril", onde ficou por cerca de dois anos, passando logo depois para sua sede atual, localizada no fim do corredor da Rheingantz (entre a antiga fábrica e as casas de

\footnotetext{
${ }_{9}^{9}$ Conversa informal com um dos fundadores da escola.

${ }^{10}$ A Fábrica Rheingantz foi o primeiro estado de previdência do Brasil. Ela foi a primeira indústria instalada na época da década de 50, no Brasil, em que os trabalhadores tinham direito à moradia, atendimento médico, creche, entre outros benefícios. A indústria tinha cerca de quatro mil funcionários, que fabricavam tecidos e, na época, foi a mais importante do Brasil.
} 
moradores). No retorno da escola aos concursos, se consagrou campeã do Grupo de Acesso ${ }^{11} \mathrm{em}$ 2008, passando no próximo ano para a disputa no Grupo Especial ${ }^{12}$, no qual tornou-se campeã do carnaval da cidade pelo Grupo Especial no ano de 2012.

Assim, optei por investigar a S.C.C. Unidos da Rheingantz pelo fato de que, atualmente, o carnaval da cidade do Rio Grande/RS do sambódromo ${ }^{13}$, encontra-se inativo e, por consequência, as escolas de samba do Grupo Especial, em sua grande maioria, não têm um grupo formado (diretoria, comissão de frente, alas, bateria, harmonia e corte). Existem, hoje, quatro escolas no Grupo Especial, e, dessas, apenas a S.C.C. Unidos da Rheingantz tem um grupo show. Este grupo é caracterizado por integrantes que representam a escola em eventos e festividades dentro e fora da cidade, dentre eles, porta-estandarte mirim e adulta, baianas, mestre sala e porta-bandeira, corte da escola juvenil, adulto, sênior e terceira idade, corte do samba, corte da bateria, corte da harmonia, rainha plussize, passistas, bateria e harmonia. Para além disso, a S.C.C. Unidos da Rheingantz é a escola na qual atuo desde 2008.

Falar, observar e pesquisar essa escola é dar visibilidade para uma comunidade que, mesmo sem ter o carnaval na cidade, busca por meio de coirmãs ${ }^{14}$ levar um pouco do que é produzido e desenvolvido no local para outras regiões e outras escolas de samba. Sendo assim, acredito que realizar uma pesquisa nessa escola foi uma possibilidade abrir visibilidades às pessoas que fazem o carnaval manter-se atuante na cidade do Rio Grande/RS.

Acompanhei a escola, realizando observação participante e registrando as informações em um diário de campo, no período de dezembro de 2018 a março de 2019. Acompanhei as rotinas, as preparações, os ensaios, as reuniões e os cuidados com o corpo diante da maratona de apresentações em eventos e desfiles que os integrantes estiveram presentes, marcando assim, o ápice do carnaval para uma escola de samba. Para além das observações, realizei, desde abril de 2019, entrevistas semiestruturadas nas quais realizei tais perguntas para as/os tituladas/os: a) Qual a tua trajetória no samba e no carnaval? b) $\mathrm{Na}$ tua opinião, existe na escola algum discurso em relação ao corpo esperado para o carnaval? Quais os discursos ou palavras percebidas em relação ao corpo no carnaval? c) Quais os preparos, hábitos, cuidados, rotinas e quanto tempo é despendido para o seu corpo e para o carnaval? d) Como você considera, entende, percebe o seu corpo dentro do contexto do carnaval na escola? e) Quais os aspectos você acha que devem ser considerados nessa escolha?

Outras perguntas foram realizadas para os diretores da escola e do grupo show, dentre elas: a) Como se estabelecem as redes de parceria com outras escolas do município ou do estado? E quais as vantagens e as desvantagens dessas parcerias? O que a escola está disposta a atender e como ficam os acordos caso não ocorra? b) Quais os critérios que utilizas para conceder títulos para os/as integrantes da escola? c) Dentre os critérios para a titulação encontra-se a idealização de um corpo para/do carnaval? d) A escola propõe ou prevê práticas de preparação/incentivo para o período que antecede às agendas para o carnaval? e) Há um investimento na preparação corporal dos componentes da escola? Isto é uma preocupação por parte da escola? f) A estética corporal tem supremacia no aspecto samba no pé?

As entrevistas foram realizadas com os integrantes do grupo show que estavam ativos na escola, entre eles: a rainha plus size, a imperatriz do samba, a soberana do samba, a rainha da escola

\footnotetext{
${ }^{11}$ São divisões inferiores do concurso de escolas de samba das cidades

12 É formado pelas melhores escolas de samba das cidades

${ }^{13}$ Lugar onde acontece o desfile das escolas de samba

14 Agremiações, sociedades, entidades que fazem parte de um grupo carnavalesco.
} 
(todas mulheres) e a presidente da escola e o coordenador do grupo show (mulher e homem), totalizando seis entrevistas.

Além das entrevistas com os integrantes do grupo show, no decorrer da pesquisa foi-se estabelecendo uma rede de informantes, dentre elas: uma destaque de escola de samba desde 1945 e uma costureira de carnaval desde 1990, ambas se mantêm ativas no carnaval, seja auxiliando as escolas, desfilando ou sendo espectadoras. Esses depoimentos auxiliaram na construção da parte histórica do carnaval da cidade do Rio Grande/RS, a partir de suas memórias.

Assim, totalizei oito entrevistas. No intuito de preservar as identidades dos/as entrevistados/as optei por utilizar pseudônimos referentes aos instrumentos que, comumente, compõem a bateria das escolas de samba. São eles: 1) Surdo, 2) Reco-Reco, 3) Repique, 4) Agogô, 5) Tamborim, 6) Cuíca, 7) Tarol e 8) Chocalho.

Todas as informações produzidas, seja a partir dos integrantes do grupo show ou da rede de informantes foram realizadas na residência dos sujeitos e captadas através de um gravador, para auxiliar no registro e transcrição das entrevistas posteriormente. Esses procedimentos foram realizados mediante a autorização dos sujeitos participantes desta pesquisa, ao assinarem o Termo de Consentimento Livre e Esclarecido (TCLE).

Entendo que, para Foucault, não existe uma metodologia correta, o que, de certa forma, pode ser mais fácil ou mais difícil, como nos lembra Veiga-Neto (2007):

Mais fácil, porque não envolve todo um conjunto de operações linguísticas e analíticas que as demais análises do discurso exigem. Mais difícil porque é preciso se "ater ao que efetivamente é dito, apenas a inscrição do que é dito", sem imaginar o que poderia estar contido nas lacunas e silêncios (p. 98).

A proposta não é a de dicotomizar as atitudes metodológicas, antes pelo contrário. $\mathrm{O}$ entendimento que preconizo é o de que toda pesquisa apresenta caminhos que nem sempre dialogam com os traços iniciais, aqueles que projetamos a priori. Contudo, é nesse inesperado exercício de produção de conhecimentos que a aventura possibilita outros saberes, em contato com outras culturas e sujeitos. E, ao me projetar nessa passarela, aprendi que, ao desconfiar das coisas que já sabia e suspender minhas verdades, consegui ampliar as possibilidades que questionar esse campo que para mim é tão caro e representativo, uma vez que, ao tratar dele, certamente, lidarei com as minhas ancestralidades.

\section{ENREDO $^{15}$ : MEMÓRIAS SOBRE OS CARNAVAIS - HISTÓRIA DO CARNAVAL NA CIDADE DO RIO GRANDE/RS}

No desenvolvimento da pesquisa foram acessadas pessoas que compuseram o que chamo de rede de informantes, que possuíam uma forte relação com o samba e o carnaval na cidade do Rio Grande/RS. Agregado a isso, as informações produzidas a partir das entrevistas, tanto da rede de informantes como dos/as titulados/as e diretores da escola, evidenciaram o vínculo familiar com a história do samba e do carnaval do Rio Grande/RS. São famílias inteiras ligadas à criação de blocos, de escolas de samba, definindo e evidenciando o samba/carnaval como um legado.

Procurando entender como a história do carnaval da cidade do Rio Grande/RS se constituiu, realizei os primeiros movimentos de busca sobre essa história por meio de três

${ }^{15}$ É o tema desenvolvido pela escola de samba, sendo um dos quesitos avaliados no desfile oficial. 
DOI: r $10.12957 /$ teias.\%Y.49589

ferramentas fundamentais: visitação à Biblioteca Riograndense, o acesso à internet e à memória de quem viveu esse início até os tempos atuais de carnaval na cidade do Rio Grande/RS.

$\mathrm{Na}$ Biblioteca Riograndense, encontrei registros que datam o ano de 1945 sobre a primeira escola de Samba da cidade do Rio Grande/RS e, coincidentemente, do estado Rio Grande do Sul. A referida cidade, além de ser a mais antiga do estado, também tem sua história marcada por fundar a primeira escola de samba. Essa, por sua vez, chamada de Escola de Samba General Vitorino, com referência à rua onde acontecia a reunião dos componentes, e na qual em 1946 aconteceu o primeiro desfile dessa escola. Um dos fundadores da escola, João Jorge de Quadros, mais conhecido como "Sardinha", ao ser entrevistado pela Comissão de Carnaval $2005^{16}$ lembra que o carnaval da cidade do Rio Grande/RS já foi um dos melhores carnavais do estado.

Diante disso, recordei alguns nomes mencionados abaixo, recorrentes nas entrevistas realizadas com a rede de informantes e com os integrantes do grupo show de escolas de samba e blocos carnavalescos, relembrando o que foi Rio Grande/RS nesta ebulição de criações de escolas de samba até os tempos atuais. Essas lembranças trazem consigo nomes importantes de agremiações/sociedades fundadas a partir de 1946, desde as primeiras movimentações, como: a própria Escola de Samba General Vitorino, Estrela do Oriente, Braço é Braço, Camelo de Bangu, Praianas, As Mariquitas, Academia do Samba Império Serrano, Bloco Almirante Tamandaré, Bloco Nega Maluca, Escola de Samba Unidos do Zaire, Dom Pedro I (CUCA), Rosa de Praia, Chaplin, Unidos da Capivara, Bloco Eles \& Elas, Nós de Casa, chegando ao carnaval da S.C.C Unidos da Rheingantz. Essa, por sua vez, se mantém ativa, mesmo no atual cenário em que se encontra o carnaval da cidade do Rio Grande, e hoje é vista como uma resistência, por tentar manter acesa a chama dessa manifestação popular/cultural.

Percebi, ao entrevistar a rede de informantes, que o carnaval de outrora deixou grandes recordações. Um carnaval que era grandioso, não por conta de desfiles de grandes carros alegóricos, mas por ser um carnaval com fantasias luxuosas, com brilhos. $\mathrm{O}$ público aguardava ansioso pelos desfiles pra ver sua escola do coração passar na avenida: "[...] Ab! a Rheingantz na avenida era tudo. A gente olhava para o entusiasmo das pessoas sentadas nas bancadas e tu dizia que era um carnaval só. Aquela gente estava dentro da Rheingantz [...] era lindo de se ver [...]” $\left(\right.$ Surdo $\left.^{17}\right)$.

As entrevistadas que compõem a rede de informantes demarcam como sendo um carnaval familiar, uma questão de pertencimento àquela comunidade e, por isso, tinha um envolvimento maior da comunidade da escola e da comunidade em geral, mesmo os que não residiam naquela localidade - e que, apeesar disso, simpatizavam com a escola e ajudavam na elaboração das fantasias, adereços, adornos, construção de alegorias, como ferreiros e soldadores.

$$
\begin{aligned}
& \text { ".... O que eu me lembro mais aquela época era da organização. Todo mundo da escola pegava } \\
& \text { junto para fazer as coisas é o que eu mais me lembro. A gente ia lá para quadra assim e todo } \\
& \text { mundo fazia...os dirigentes diziam: V amos nos juntar para fazer a ala tal, todo mundo se } \\
& \text { juntava. Claro, as costureiras faziam o que tinham para fazer e a gente fazia as alegorias tudo, }
\end{aligned}
$$

\footnotetext{
16 A entrevista, na íntegra, está disponível em: $<$ http://www.riogrande.rs.gov.br/pagina/index.php/noticias/detalhes +7a01,premiacao-do-carnaval homenagearafundador-da-primeira-escola-de-samba-do-rs.html\#.W_ahuOhKjIU> realizada pela Comissão do Carnaval de 2005, quando "Sardinha" recebeu uma homenagem por ser um dos responsáveis a colocar a cidade em evidência atuando com dedicação ao carnaval da cidade do Rio Grande.

17 Para preservar a identidade dos sujeitos de pesquisa e garantir anonimato, os mesmos serão identificados como instrumentos da bateria de uma escola de samba, como por exemplo reco-reco, tamborim, chocalho, agogô entre outros. No corpo do texto as falas serão apresentadas em itálico.
} 
não interessava se eu saía naquela ala ou não, aquele dia todo mundo se juntava e faria para todo mundo, sabe? Isso é o que eu mais me lembro, ficava cheio a quadra de gente fazendo e ajudando a escola [...]" (Reco-Reco).

Outro relato interessante refere-se ao fato de que, naquela época, as escolas se preocupavam com as fantasias, principalmente aquelas que tinham pontuação: comissão de frente, destaques, mestre-sala e porta-bandeira, bateria, rainhas. Essas, por sua vez, tinham reservavam o corpo, geralmente, com meias arrastão, capas, maiôs. As rainhas desfilavam e apresentavam suas escolas com muita ginga e samba no pé, como fica evidenciado nesta fala:

"[...] Antigamente para Rainha não tinha eleições, era o que o presidente escolbia e diz̧ia que tu ias ser Rainha e pronto. Não tinha aquela coisa de votação, qual mais bonita, qual mais feia, corpo assim, assado, sabendo sambar representava a escola, porque naquela época o samba era exaltado e girava em torno do carnaval [...]" (Surdo).

O "samba no pé!". Em que momento o corpo foi ganhando espaço neste meio, deixando o samba no pé como segunda opção? Esse movimento remete-me à fala de Foucault (1986, p. 56) quando diz que "[...] gostaria de mostrar, por meio de exemplos precisos, que, analisando os próprios discursos, vemos se desfazerem os laços aparentemente tão fortes entre as palavras e as coisas". Ou seja, não é apenas o samba propriamente dito. Não é qualquer samba! Não é qualquer coisa! É o samba no pé, que moveu o samba e fez com que o ritmo ganhasse vida e movimento. Foi uma demarcação histórica, uma relação de pertencimento com o legado do samba. É uma palavra que, sozinha, tem um sentido, mas que levando em consideração seu contexto, esse "mais" é permeado de significados e sentidos. Segundo o mesmo autor,

[...] como práticas que formam sistematicamente os objetos de que falam. Certamente os discursos são feitos de signos; mas o que fazem é mais que utilizar esses signos para designar coisas. É esse mais que os torna irredutíveis à língua e ao ato da fala. É esse "mais" que é preciso fazer aparecer e que é preciso descrever (FOUCAULT, 2009, p. 55).

Essas falas evidenciam que a presença e a prevalência do corpo dentro do samba foram sistematicamente construídas. O corpo, dentro do samba, não era o foco. Essa movimentação que passou a dar centralidade para o corpo evidencia o que Goellner (2008) afirma sobre ser/ter corpo, pois as representações de corpos são sempre temporárias e variam conforme o lugar e o tempo em que este corpo circula.

O carnaval dos anos 1950, até um determinado momento, foi constituído por "samba no pé" e fantasias. Fato esse que pode ser evidenciado por meio das vestimentas (Figura 1 e 2) utilizadas pelas sambistas, as quais eram mais cobertas, deixando à mostra a beleza da fantasia, do gingado, da desenvoltura representando a escola do coração. 
DOI: r 10.12957/teias.\%Y.49589

Figura 1: Exemplo de fantasias utilizadas pelos participantes da rede de informantes

Rainha do Carnaval da cidade do Rio Grande/RS - 1976.

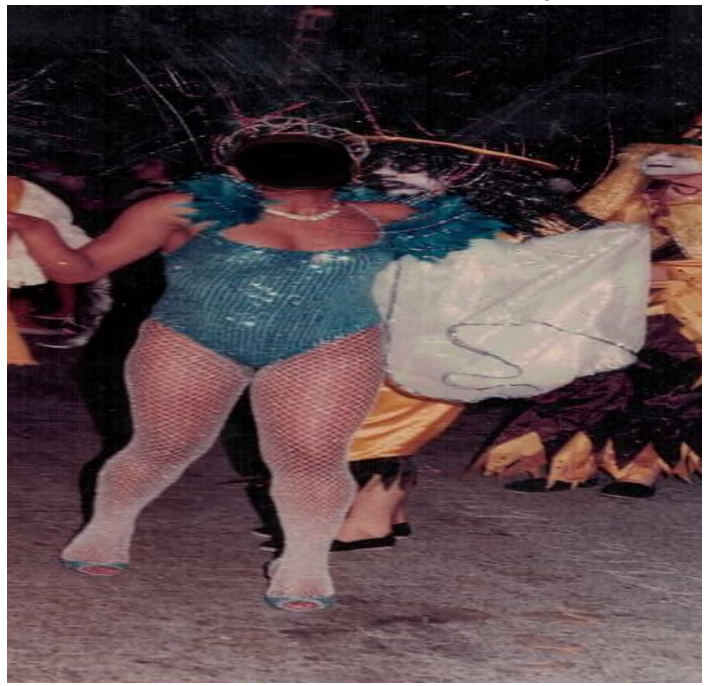

Fonte: Arquivo pessoal, rede de informantes.

Figura 2: Exemplo de fantasias utilizadas pelos participantes da rede de informantes Sambista Conjunto Acadêmico Imperadores do Samba da cidade do Rio Grande/RS - 1976.

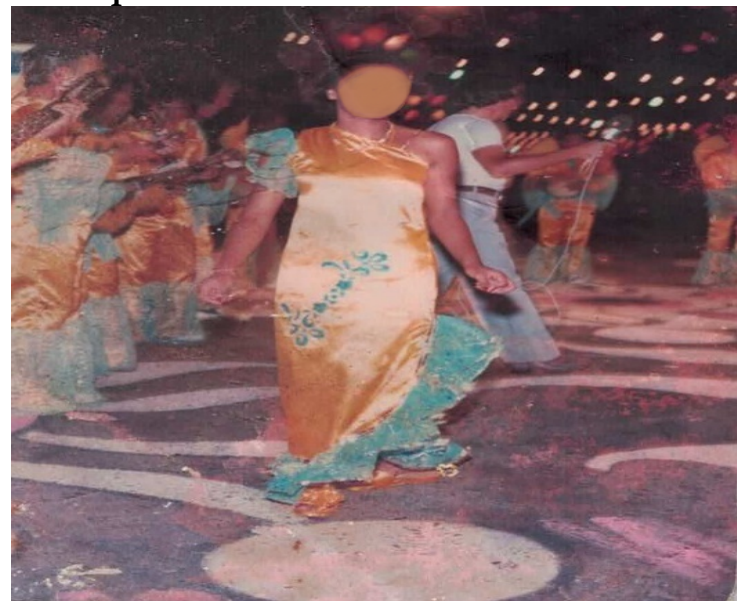

Fonte: Arquivo pessoal, rede de informantes

\section{O CORPO NO/PARA O CARNAVAL NOS TEMPOS ATUAIS}

Diferentemente do que apurei com os relatos das memórias sobre o carnaval, atualmente, o corpo do carnaval é um corpo que ganha maior visibilidade e atenção, uma vez que a busca por corpos perfeitos ou magros vêm sendo objeto de desejos entre os diretores de carnaval. Para Sohn (2006):

Nunca, antes do século XX, o corpo sexuado fora objeto de cuidados tão atenciosos. Cada um o exibe, o corpo está onipresente no espaço visual, ocupa igualmente um papel sempre maior nas representações tanto científica como 
midiáticas. Chegando o mesmo a se tornar um desafio médico e comercial (SOHN, 2006, p. 109).

A busca incessante por um modelo de corpo gera entre as tituladas um desejo de se ter e manter um padrão de corpo, nem que para isso sejam necessárias longas jornadas de exercícios e restrições alimentares. A fim de se encaixar na lógica de corpo perfeito, exposto pela mídia televisiva, ao enfatizar as rainhas e musas de escolas de samba para o carnaval, esquece-se assim a maior motivação da manifestação que é o samba no pé, como podemos observar na fala a seguir:

"[...] Infelizmente a escola é muito exigente, mas não acho que seja só a minha escola. O pessoal
visa mais o corpo, a aparência, e às vezes deixa o samba de lado. Já ouvi muito: ab, se tu
emagrecesses irias ficar mais bonita [...] quando eu emagreci infelizmente ouvi que estava magra
demais, ou seja, tu nunca está bem e isso é muito triste. Eu cheguei a enlouquecer fazendo
academia, fazendo um monte de coisa e cheguei à conclusão que nunca vamos agradar a todos
[...]" (Tamborim).

Contudo, observei que nem sempre foi assim. Pensando no ano de 2008, quando a escola retorna ao carnaval e tem sua primeira diretoria formada, os responsáveis tinham um olhar voltado para o samba no pé, como destacado nas seguintes falas:

\footnotetext{
"[...] na escola em si, eles olham os corpos como pessoas magras! Para sambar tem que ser magro. Para ser bonito o show tem que ser magro [...] nem sempre foi assim [...] em outras diretorias não era envolvido com o corpo e sim com o samba. Se a pessoa sambava, ok!! [...]" (Agogô).

"[...] Existe...existe [...] se eu emagrecer a escola consegue apostar em mim, em roupa, em me arrumar melhor, em me ajudar a estar melhor nas apresentações né, mas isso se eu emagrecer […” (Cuíca).
}

Verifiquei que as práticas discursivas que permeiam os espaços da escola perseguem um modelo de corpo dito "perfeito" para o carnaval. São olhares que julgam, gestos que insinuam, falas que insultam e pensamentos que se culpam. Assim, é possível perceber que os olhares que julgam e os discursos praticados no interior da escola, onde estão sempre presentes, envolvidos como os integrantes, sambistas, passistas se comportam e de que maneira estão representando a escola. Em suma, como pode ser observado no fragmento abaixo:
"[...] tu ouve as pessoas dando piadinhas e tal não só ali na escola, te olham assim como, tipo [...] só não abrem a boca pra dizer porque pode gerar até um caso via judicial, então as pessoas não te falam, mas pelo o olhar delas, por alguns gestos, por algumas conversinhas ao pé do ouvido do outro, tu percebes que as pessoas estão ali, meio que te aturando dizendo assim, o que que essa mulher está achando que ela épara estar fazendo isso? Só ela acha que está agradando né $[\ldots]$ ”. (Repique).

Nota-se, na fala dessa entrevistada, que a mesma se tornou uma "resistência" nesse espaço, procurando fazer o que gosta. Mas, para isso, ela precisa ignorar esses olhares e julgamentos, deixando o sentido e o sentimento do carnaval falar mais alto. Dessa forma, precisa romper barreiras e enfrentar preconceitos, como prossegue na seguinte fala:

\footnotetext{
"[...] mas eu como nunca dou importância para isto, eu chego lá e visto a personagem e faço o que eu tenho que fazer [...] que no caso é sambar, me apresentar lá conforme a gente combina tudo, mas eu tô lá enfrentando todos esses olhares e esses preconceitos que as pessoas tem, mas tem e não épouco. Eu não me via com as características certas para fazer parte do grupo show.
} 
Olhando de fora, tu via meninas novas e com corpão...até que um dia meti as caras e fui perguntar e deu certo [...]" (Repique).

Em todos os lugares somos subjetivados, produzidos através dos discursos. Entendo a escola como lugar e tempo de produção de corpos. Nela encontram-se impressas, "[...] um conjunto de regras facultativas que são oferecidas como modelos, por um conjunto de práticas técnicas e exercícios nos quais o indivíduo oferece-se a si próprio como objeto de conhecimento e cuidado a fim de transformar o seu próprio modo de ser e conduzir-se" (GARCIA, 2002, p. 28).

Quando questionadas se já deixaram de se apresentar em eventos por não se enquadrarem no padrão que a escola diz ser o ideal, ou que ela discursa sobre o corpo esperado para o carnaval, algumas entrevistadas emitiram respostas que indicam exclusão/restrição por parte daquelas que compunham grupo show. Como destacado nos seguintes excertos:

$$
\begin{aligned}
& \text { "[...] Sempre fui mesmo não estando no perfil”" que se ouvia [...] só deixei de ir mesmo quando } \\
& \text { não fui convidada [risos] mas vejo que outras pessoas deixam de ir por não estar se sentindo } \\
& \text { bem [...]” (Agogô). } \\
& \text { "[...] Sim, já deixei de ir }[\ldots] \text { seja pela questão das roupas (roupas bonitas e com pedrarias), } \\
& \text { pelo corpo por ouvir que [...] tem que dar uma emagrecida para poder ficar bem na roupa. Não } \\
& \text { me sentia adequada com as exigências então preferia não comparecer [...]” (Tamborim). } \\
& \text { "[...] Sim, já deixei de sair muitas vezes. Não só por falta de verba né, mas também porque } \\
& \text { falam sobre ir bem arrumado, cheios de pedrarias [...] sugerem tecidos para ficar mais magro } \\
& {[\ldots . .] \text { para não fica com a barriga solta [...] porque vai estar fulano, ciclano e vão estar te olhando }} \\
& {[. . .] \text { (Cuíca). }}
\end{aligned}
$$

Neste sentido, Giannattásio (2012) escreveu que é sobre o corpo, essa materialidade biológica que "[...] se vinculam, por exemplo, todas as formas de ascetismo, a querela nas relações entre matéria e espírito até às dimensões da cultura e da linguagem” (GIANNATTTÁSIO, 2012, p. 19). De modo amplo, os corpos serão disciplinados, a partir de contextos e usos específicos. Além disso, é sobre eles que os imperativos que envolvem padrões e/ ou noções de beleza. Sem neutralidade alguma, a filosofia da linguagem, ao produzir e identificar corpos, age sob aparatos que "[...] são endereçados a sujeitos de determinado tipo, com certa visão do mundo, com certo quadro de valores morais” (MENDES, 2006, p. 177). A produção e validação dos tipos corpóreos correspondem a períodos sócio-históricos muito específicos e nunca escapam de formações discursivas generalizadoras.

Os discursos são direcionados com intencionalidade para chegar às pessoas que fazem parte de determinada posição ou função. Neste caso, dentro da escola, é perceptível os meios em que processam esses direcionamentos e essas intencionalidades. Em contrapartida, observei, na fala dos diretores, ao serem questionados sobre a estética corporal e sua possível supremacia no aspecto samba no pé, que seus entendimentos são de outra ordem, divergindo das demais entrevistadas.

\footnotetext{
"[...] Eu acho que sim! Porque hoje o samba no pé é importante é muito importante, mas hoje tem muito jogo de corpo né. Tu falas com o teu corpo, tu falas com o teu olhar, tu falas com o teu samba. Não adianta tu chegar numa avenida ou num show e tu sambar, sambar, sambar. Tem que ter a comunicação com o público. Porque se tu sambares, sambar, sambar, ninguém vai te notar. A passista hoje também é uma atriz [...] ela também tem que encenar né [...] todo um jogo de corpo, de olhares [...] de tudo [...]" (Tarol).
} 
O segundo entrevistado, que compõe a diretoria da escola, afirma que:

\begin{abstract}
"[...] Não! Não porque eu já vi caso de uma gordinha botar uma magra bombada linda, no chinelo. Chinelo que eu digo no jeito de sambar. Eu já vi uma gordinha roubar a cena de uma mulher linda de morrer, sambando. Porque é como eu já falei foi-se o tempo que era o corpo. Foi-se o tempo que as pessoas usavam o corpo, o cabelo, o padrão branco do olho azul, ou a morena magra do cabelão liso. Hoje em dia, o bonito é ser natural [...] O "bonito", o "elegante", é isto [...]”" (Chocalho).
\end{abstract}

Ou seja, não existe um critério evidente na visão desses que escolhem, elegem, reelegem, posicionam e direcionam as tituladas do seu grupo show. Questionados sobre a possibilidade de ter um título excedente para compor alguma corte e ter uma pessoa interessada a fazer parte da escola ou do grupo show, porém, esta pessoa não sabe sambar e não tem um corpo bonito. Nesse caso, perguntamos como ficaria a escolha por um/a titulado/a?

$$
\begin{aligned}
& \text { "[...] Ah não, mas aí ela não pode fazer parte do grupo, aí ela não tem nada! Se ela não tem } \\
& \text { um corpo legal, se ela não tem o samba no pé, então ela não pode. Às vezes a escola dá titulo } \\
& \text { por uma necessidade. Tem outros titulos que a gente escolhe sim, tem que escolher no conjunto. } \\
& \text { As vezes tem a necessidade de ter aquele cargo e a pessoa não se enquadrar em tudo, mas a } \\
& \text { gente tem a necessidade de ter aquele cargo porque a gente tem que apresentar aquele cargo para } \\
& \text { a sociedade, para outras entidades que a gente vai se apresentar. Então às vezes a gente abre } \\
& \text { uma exceşão para colocar aquela pessoa ali [...]” (Tarol). }
\end{aligned}
$$

E, continuou, ao responder sobre a idealização de um corpo para o carnaval:

“[...] Hoje os padrões pedem muito para ter um corpo [...] antigamente já não, as passistas vinham [...] eram mais naturais. [...] Hoje [...] a sociedade exige muito para elas serem perfeitas, a sociedade! E dentro de uma escola de samba, às vezes sem a gente querer a gente vai pelo padrão de que a sociedade exige. E, eu enquanto diretoria não idealizo. Eu idealizo o amor a escola [...] se a pessoa está se sentindo bem eu não vou dizer para a pessoa, faz isso faz. aquilo [...]" (Tarol).

“[...] Não, eu não utilizo isso dai até porque o carnaval não se faz só de corpo. Eu para o grupo show assim o que eu falo [...] quando en quero a pessoa para perto de mim eu procuro a pessoa que além de gostar de samba, gostar da minha entidade, gosta do men pavilhão [...]” (Chocalho).

As escolhas acontecem de forma aleatória, ora pelo samba, ora pelo corpo/aparência, ora pela necessidade, ora pela expressão corporal, ora pela postura ou até mesmo pelo amor ao samba. Não existe entre eles um padrão de escolha, mas existe um padrão para quem quer entrar e se manter com o título dentro da escola. Foi recorrente nas falas das entrevistadas relatos que indicam tentativas de abandono da escola por não estar neste padrão, existindo assim um embate entre titulados/as e diretoria, sendo os/as titulados/as subjetivados/as a todo instante a fim de tentar se encaixar e "agradar" seus diretores.

A ênfase na liberdade do corpo no que respeita a sua exposição e desnudamento nos espaços públicos caminha passo a passo com a valorização dos corpos enxutos e "em forma" onde o excesso, mais que rejeitado, é visto, por vezes, como resultado da displicência e da falta de cuidado. Pensando com Foucault, nesse novo investimento sobre o corpo já não há mais a forma de controlerepressão, tão comum aos séculos XVIII e XIX, mas o controle-estimulação 
porque a valorização e a exploração do corpo são faces de uma mesma moeda (GOELLNER, 2008, p 38-39).

Nos excertos, encontrei a potência dos discursos que constroem sujeitos e modos de ser e de agir. Garcia (2002), destaca que os “[...] processos de subjetivação dão-se incessantemente em diversos lugares e segundo regras que se confrontam com indivíduos livres que a eles aderem, ou não, em função dos estilos de vida e dos modos de existência que se deseja levar" (GARCIA, 2002, p. 28). Essa relação estabelece um tensionamento que permite ajustes, disputas, rupturas, pois implica os desejos de pertencimento, de conquista e/ou superação diante dos desafios pelos quais são submetidos/as.

\section{APURAÇÃO E DESFILE DAS CAMPEÃS: PARA TUDO ACABAR NA QUARTA- FEIRA!}

A construção desta pesquisa possibilitou-me a compreensão de que o carnaval na escola inicialmente foi constituído de samba no pé e fantasias. Contudo, a partir das falas dos integrantes do grupo show e da rede de informantes, percebi que atualmente são elencados outros adjetivos para se ter e pensar o corpo do carnaval. A reflexão constituída ao longo desta investigação permitiu-me visualizar a ênfase e o apogeu do corpo a partir de um consumo global que padroniza, define os incluídos e os excluídos, influenciando em todas as esferas sociais o corpo idealizado e, por consequência, o corpo a ser construído/perseguido. Contudo, adotadas as devidas proporções de grandiosidade e de adesão das comunidades, em contextos menos privilegiados para a produção de um carnaval dessa natureza, a realidade ainda permita disputas, enfrentamentos, uma vez que escolas de menor porte e aporte financeiro ainda dependem, fortemente, das comunidades ou de políticas públicas de cultura que permitam a existência do carnaval, mantendo, desse modo, a diversidade e/ou pluralidade de corpos.

Além disso, também entendi que os processos de titulações dentro das escolas constituemse como relações de poder, atravessados por jogos de interesses que estão intrincados com essas articulações de escolher, de eleger, de titular e "destitular" determinados tipos de corpos ou pessoas. No meu entendimento, considero que esta pesquisa tenha contribuído para que os integrantes do grupo show pudessem problematizar e perceber como eles produzem seus corpos para o carnaval. Ao final das entrevistas, após todas as indagações e os questionamentos, os mesmos manifestaram reflexões sobre suas identidades e seus desejos dentro do samba e do carnaval de modo que sejam respeitadas no contexto escola de samba. Além disso, esta pesquisa contribuiu também para o âmbito acadêmico da Educação Física, promovendo dessa forma um olhar sobre o corpo e carnaval, refletindo de que maneira são produzidos esses corpos no interior de uma escola de samba.

\section{REFERÊNCIAS}

CORTÊS, Gustavo Pereira. Dança, Brasill: Festas e danças populares. Belo Horizonte/MG: Leitura, 2000.

FOUCAULT, Michel. A arqueologia do saber. [Trad.] Luiz Felipe Baeta Neves. 7. ed. Rio de Janeiro/RJ: Forense Universitária, 2009.

FOUCAULT, Michel. A arqueologia do saber. Rio de Janeiro/RJ: Forense Universitária, 1986. 
DOI: r 10.12957/teias.\%Y.49589

GARCIA, Maria Manuela Alves. Pedagogias críticas e subjetivação: uma perspectiva foucaultiana. Petrópolis/RJ: Vozes, 2002.

GIANNATTASIO, Gabriel. O corpo em Sade e Nietzsche: ou, quem sou eu agora? [Ensaios] Gabriel Giannattasio. Londrina: EDUEL, 2012.

GOELLNER, Silvana Vilodre. Corpo, gênero e sexualidade: um debate contemporâneo na Educação. 4. ed. Petrópolis, RJ: Vozes, 2008.

LE BRETON, David. Adeus ao corpo: Antropologia e sociedade/ David Le Breton; [Trad.] Marina Appenzeller. 6. ed. Campinas/SP: Papirus, 2013.

MENDES, Cláudio Lúcio. O corpo em Foucault: Superfície de disciplinamento e governo. Revista de Ciências Humanas, Florianópolis, n. 39, p. 167-181, 2006.

NEGRINE, Aiton. A pesquisa qualitativa na Educação Física: alternativas metodológicas. Augusto Nibaldo Silva Trivinos (Org.) et al. 2. ed. Porto Alegre: Editora da UFRGS/ Sulina, 2006.

SOHN, Anne-Marie. História do Corpo: As mutações do olhar: O século XX/ sob direção de Alan Corbin; Jean Jackues Courtinne; Georges Vigarello; [Trad. e Rev.] Ephraim Ferreira Alves. 4. ed. Petrópolis/ RJ: Vozes, 2011.

VEIGA-NETO, Alfredo. Foucault \& a Educação. 2 ed. 1 reimp. Belo Horizonte/MG: Autêntica, 2007.

Submetido em marco de 2020

Aprovado em outubro de 2020

\section{Informações dos autores:}

Priscila Fontes Gularte

Universidade Federal do Rio Grande

E-mail: priscila.fontesg@gmail.com

ORCID: https://orcid.org/0000-0002-0352-7794

Link Lattes: http://lattes.cnpq.br/2399906299934369

Leila Cristiane Pinto Finoqueto

Professora Adjunta do curso de Educação Física no Instituto de Educação (IE) da Universidade Federal do Rio Grande (FURG)

E-mail: cristianefinoquetto@gmail.com

ORCID: https://orcid.org/0000-0001-5917-1152

Link Lattes: http://lattes.cnpq.br/2223061140488670

Rodrigo Lemos Soares

Doutorando do Programa de Pós-graduação em Educação da Faculdade de Educação da Universidade

Federal de Pelotas (UFPel)

E-mail: rodrigosoaresfurg@gmail.com

ORCID: https://orcid.org/0000-0002-1690-8991

Link Lattes: http://lattes.cnpq.br/7158430253302821 